\title{
Self-efficacy for dietary behaviour concerning heart disease among Alexandria school pupils
}

G.M. Mounir, I.M. Fatohy ${ }^{2}$ and N.H. Mahdy ${ }^{3}$

$$
\begin{aligned}
& \text { الكقاءة الذاتية في السلوك الغذاتي فيما يتعلق بأمراضي القلب بين تلاميذ المدارس في الإسكندرية. }
\end{aligned}
$$

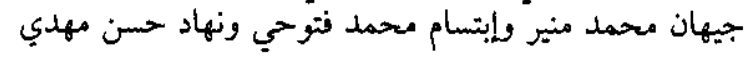

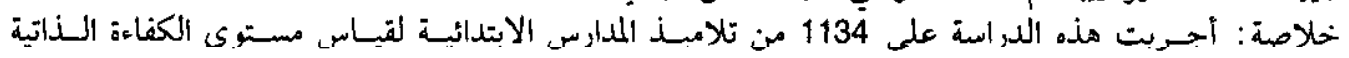

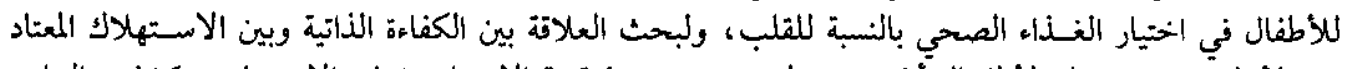

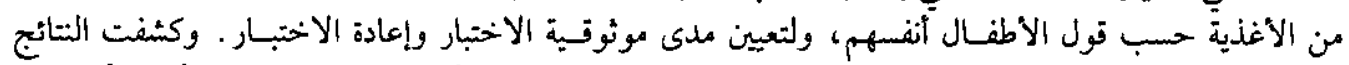

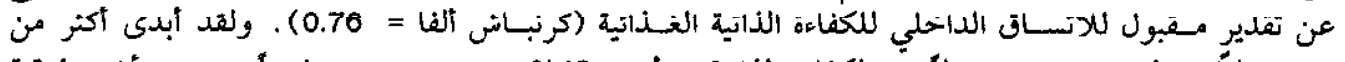

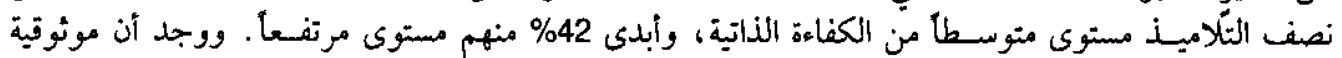

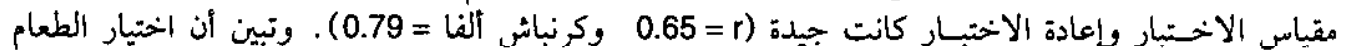

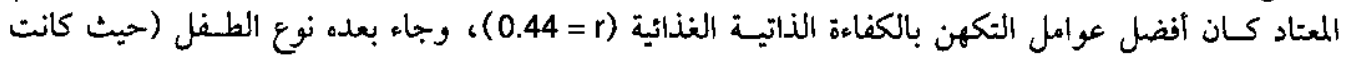

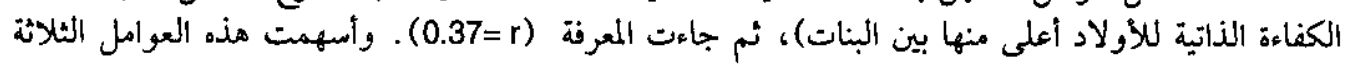
في تفسير 25\% من التباين.

ABSTRACT A study of 1134 preparatory-school pupils was conducted to measure children's seif-efflcacy for selecting healthy food for the heart, to examine the relationship between self-efficacy and self-reported usual food consumption and to estimate test-retest reliablity. Results revealed an acceptable estimate of internal consistency of dietary selt-efficacy (Cronbach alpha $=0.76$ ). Over half the students exhibited a moderate level of self-efficacy and $42 \%$ a high level. Test-retest reliablity of the scale was good $(r=0.65$, Cronbach alpha $=$ 0.79 ). Usual food choice was the first best predictor of dietary self-efficacy $(r=0.44)$, followed by sex (boys had higher self-efficacy than girls) and then knowledge $(r=0.37)$.The three factors contributed to explain $25 \%$ of the variance.

L'efficacité personnelle à l'égard du comportement alimentaire concernant la cardiopathie chez des élèves à Alexandrie

RESUME Une efude a éte realisee aupres de 1134 élèves des écoles préparatoires en vue de mesurer l'autoefficacité perçue des entants dans le choix d'aliments sains pour le coeur, d'examiner la relation entre l'autoefficacité perçue et la consommation alimentaire habituelle rapportée par les intéressés et d'estimer la fiabilité utest-retest» de l'échalle de mesure. Les résultats ont indiqué une estimation acceptable de la cohórenco interne de l'efficacité personnelle en matière d'alimentation (alpha de Cronbach $=0,76$ ). Plus de la moitié des élèves montraient une auto-efficacité modérée et $42 \%$ une auto-efficacité élevée. La fiabilité rtest-retest” de l'échelle de mesure était bonne $(r=0,65$, alpha de Cronbach $=0,79)$. Le choix habituel des aliments était le premler tacteur qui permettait te mieux de predire l'auto-efticacite en matière d'alimentation $(r=0,44)$, suivi par le sexe (les garçons avaient une auto-efficacité supérieure aux filles) puis les connaissances $(r=0,37)$. Ces trois facteurs permettaient d'expliquer $25 \%$ de la variance.

\footnotetext{
'Department of Family Health; ${ }^{2}$ Department of Health Administration and Behavioural Science:

3 Dopartmont of Biostatistics, High Inetituto of Publio Hoalth, Alexandria University, Alexandria, Egypt.

Received: 12/03/98; accepted: $12 / 07 / 98$
} 


\section{Introduction}

Coronary heart disease is a major cause of morbidity and mortality. It is the commonest cause of death in both sexes worldwide [1]. Evidence that heart disease develops in response to a diet high in saturated fat, cholesterol and salt should encourage liealthier behaviour early in life [2].

Diet patterns appear to be learned at an early age, suggesting the need for health promotion within schools [3]. Interventions during childhood are intended primarily to promote behaviours which, if continued into adulthood, will reduce the risk of cardiovascular diseases (CVD) by delaying or preventing physiological degeneration, such as fatty deposition in coronary arteries and elevated blood pressure [4].

Social psychology models that identify envitonmental, individual and behavioural characteristics associated with CVD have helped to guide the development of chronic disease prevention programmes among children and youth $[5,6]$.

Social cognitive theory implicates selfefficacy, which refers to one's belief in one's ability to adopt a specific behaviour [7]. People with strong self-efficacy expectations in a particular domain approach tasks as challenges rather than threats, persist when their efforts fail, feel in control of potential stressors and maintain commitment to goals [8].

The child and adolescent trial for cardiovascular health (CATCH) includes an intervention component to improve child nutrition by lowering total fat and sodium in the diet. CATCH intervention efforts, based on the principle of social cognitive theory and organizational changes, emphasize modelling, self-efficacy, skill-building and behavioural competency while targeting social influences and environmental opportunities to pronnote cardiovascular health among students [9]. Process evaluation (based on health education methods and materials) and impact evaluation (based on the effect of health education on knowledge, attitude and behaviour) of such interventions can improve school-based health education programmes, planning, evaluation and ultimately will decrease behavioural risk factors for CVU among children [8].

The aims of the present work were to measure the self-efficacy of pupils for usua] food (foods usually eaten by the pupils) consumption as it relates to fat and sodium intakes, to examine the relationship between self-efficacy and self-reported usual food consumption among pupils, and also to estimate test-retest reliability for the self-efficacy scale.

\section{Subjects and methods}

\section{Sample selection}

A representative multistage stratified random sample of pupils in the second grade of preparatory schools in Alexandria was selected. The stratification was based on educational regions, type of school and sex. Alexandria governorate is divided into six districts. The schools in each district were divided into two strata, governmental and private schools. Using an equal allocation technique, two schools from each stratum were selected randomly; one for boys and another for girls. The total number of schools selected was 24 . One class from the second grade was selected randomly from each school and all the pupils were included in the study. The total sample amounted to 1134 pupils. 


\section{Instrumentation and procedures}

Data were collected through the administration of a predesigned questionnaire to the pupils as a class activity, so all pupils were encouraged and expected to participate. Pupils were instructed to use a cover sheet for their responses and not to answer out loud. The importance of honest answers was emphasized. During administration, the researcher walked around the classroom to ensure that the instructions were understood.

The questionnaire was designed to elicit information on the pupils' personal and socioeconomic situation and their health behaviour. For the latter, a questionnaire related to health behaviour was developed and pilot tested to measure several psychosocial constructs such as knowledge, selfefficacy and usual behaviour related to diet among preparatory-school pupils. A child dietary self-efficacy scate was developed after literature review $[8,10]$. Thus, the questionnaire consisted of the following parts.

- Personal and socioeconomic data which included age, sex, birth order, level of education and occupation of the parents, family size, estimated economic level and the presence of audiovisual equipment (television, radio) in the house. All the previous items were scored and modified after the model developed by Fahmy and El-Sherbini [ $l l]$. The total socioeconomic score was 29 and scores $\geq 25$ indicated high socioeconomic level; scores of 20-24 middle level and scores $<20$ indicated low socioeconomic level.

- The knowledge scale which consisted of 12 items concerning the pupils' knowledge about which food was more healthy, i.e. had high or low salt or fat. Each item consisted of two choices and was scored as 2 for the right answer and
0 for the wrong or don't know, except for the question which asked about which food was the most healthy: without salt (2), with a little salt (1) and with a lot of salt or don't know (0). Thus the total score ranged from 0 to 24 , and was classified as follows: satisfactory (19 or more), fair (12-18) and poor (<12).

- The child dietary self-efficacy scale which measured the latent construct of the children's self-confidence in their ability to choose lower fat, lower sodium foods rather than high fat or high sodium food products. The scale included 17 items which were chosen to represent common food choices which, if acted upon, could potentially lower fat and sodium intake anong this age group. Responses were classified according to a three point Likert-type format with the options of: not sure, a little sure or very sure, with scores of 1-3. The total score ranged from 17 to 51 and was classified as follows: high level (40 or more), moderate (28-39) and low level (17-27).

- The behaviour questionnaire (usual food choices scale) which was based on the self-reported dietary behaviour as it pertained to fat and sodium consumption. This scale included 17 items; each item was scored 0 for higher intake of fat or sodium and 2 for lower fat/lower sodium intake, except for the question on which foods were eaten more often; without salt (2), with little salt (1) and with a lot of salt (0). Thus the total score ranged from 0 to 34 and was classified as: poor dietary behaviour $(<11)$, average (11-22) and good (23-34).

A total of 1068 pupils completed the self-efficacy questionnaire and 1032 completed the behaviour questionnaire. The total questionnaire required approximately 20-30 minutes to complete. The child di- 
etary self-efficacy scale was administrated twice, two weeks apart, to examine test-retest reliability; 736 of the participants completed the whole retest questionnaire.

\section{Statistical analysis}

Data were analysed using SPSS (version 6.0 ). Percentile coefficients of skewness and kurtosis were used to test the distribution of the data. The data proved to be normally distributed so parametric statistics were preferred.

The chi-squared test of independence was used to assess sex differences in psychosocial factors (knowledge, behaviour and self-efficacy) with the subsequent Cramer's $V$ for testing the strength of the association.

A principal components factor analysis with varimax rotation was carried out to estimate factorial validity, which is a type of construct validity of the self-efficacy scale in which squared multiple correlation is used as the prior communality estimates and Kaiser's criterion applied (eigenvalue $>1$ extraction) where the eigenvalue is the total variance explained by each factor. The rationale for Kaiser's criterion is that a factor should account for more variance than any single variable.

The Levene test of equality of variances and Student $t$-test were performed to test the difference in the overall mean scores by sex. ANOVA with subsequent multiple comparison (Tukey B test) was used to assess the differences in the mean scores by social class.

Reliability of the scale was assessed in terms of internal consistency. Cronbach alpha was computed; a coefficient alpha of 0.70 was considered as adequate.

Test-retest reliability was also assessed using Cronbach alpha, Pearson correlation coefftcient, percent agreement and Hotelling T-squared.
To obtain an estimate of convergent validity, a correlation analysis was used to make inferences about the relationship between the two constructs, dietary self-efficacy and usual food choices. In addition, the concurrent form of criterion-related validity was investigated through stepwise multiple regression analysis.

Stepwise multiple regression analysis was adopted for three models. In the first model, the knowledge score was the dependent variable and the independent variables were: $\operatorname{sex}\left(x_{1}\right)$, birth order $\left(x_{2}\right)$, family size $\left(x_{3}\right)$, education of the mother $\left(x_{4}\right)$ and the presence of audiovisual equipment $\left(x_{5}\right)$. In the second and third models, the self-efficacy and behaviour scores respectively were the dependent variables and the same independent variables in the first model were included, in addition to knowledge score $\left(x_{6}\right)$, behaviour score in the second model $\left(x_{7}\right)$ and self-efficacy score in the last model $\left(x_{\mathrm{g}}\right)$.

\section{Results}

\section{Demographic characteristics of the sample}

A total of 1134 pupils participated in the study. Their mean age was 13.14 years $(\mathrm{SD}=0.76)$. The sample comprised 581 boys $(51.2 \%)$ and 553 girls (48.8\%). With regard to birth order, about $40 \%$ of the pupils were the first child in the family, $31.4 \%$ were the second child, $18.1 \%$ and $10.1 \%$ were the third and fourth children or more. As regards social class, $23.3 \%$ were in the low socioeconomic class, $17.7 \%$ were middle class and $59.0 \%$ were in the high socioeconomic group.

\section{Dietary knowledge for heart health}

Almost $24.7 \%$ of the pupils displayed a satisfactory level of awareness of heart health, 
$56.2 \%$ had a fair level and $19.1 \%$ had a low level. Table 1 shows that the percentage of correct responses ranged from about 30\% to $96 \%$. The question for which the lowest percentage of pupils gave the correct answer $(30 \%)$ was about the relative healthiness of cereals compared to nuts, with a similarity of response in both girls and boys. Less than one-third of the pupils knew that low fat milk was more healthy than high fat milk (buffalo milk), with greater awareness among girls than boys (37.6\% and $23.6 \%$ respectively); the differ- ence was statistically significant, but with a weak association $\left(\chi_{1}^{2}=26.36, P<0.05\right.$, $V=0.15$ ). Over $60 \%$ of the pupils knew that boiled potatoes were more healthy than fried potatoes or crisps; boys were more likely than girls to answer this question correctly $(68.3 \%$ and $59.0 \%$ respectively) $\left(\chi_{1}^{2}=10.79, P<0.01\right)$. The question for which the highest proportion of pupils gave the correct answer (about 96\%) was about the relative healthiness of fresh fruit compared to candy bars.

Table 1 Distribution of the pupils according to their correct answers to the knowledge item questionnaire by sex

\begin{tabular}{|c|c|c|c|c|c|c|c|}
\hline \multirow{3}{*}{$\begin{array}{l}\text { Knowledge item (which } \\
\text { food is more healthy?) }\end{array}$} & \multicolumn{6}{|c|}{ Correct answer } & \multirow{3}{*}{$\begin{array}{l}\text { Test of significance } \\
\chi_{4}^{2}\end{array}$} \\
\hline & \multicolumn{2}{|c|}{$\begin{array}{l}\text { Males } \\
(n=581)\end{array}$} & \multicolumn{2}{|c|}{$\begin{array}{l}\text { Females } \\
(n=553)\end{array}$} & \multicolumn{2}{|c|}{$\begin{array}{c}\text { Total } \\
(n=1134)\end{array}$} & \\
\hline & & $\%$ & No. & $\%$ & No. & $\%$ & \\
\hline $\begin{array}{l}\text { With a lot of salt or minimal or } \\
\text { no salt }\end{array}$ & 468 & 80.6 & 430 & 77.8 & 898 & 79.2 & 1.34 \\
\hline Fresh or canned vegetables & 443 & 76.2 & 454 & 82.1 & 897 & 79.1 & $V=0.07$ \\
\hline $\begin{array}{l}\text { Vegetables and salad or } \\
\text { hamburger and fried potatoes }\end{array}$ & 491 & 84.5 & 460 & 83.2 & 951 & 83.9 & 0.37 \\
\hline Low fat milk or high fat milk & 137 & 23.6 & 208 & 37.6 & 345 & 30.4 & $\begin{array}{l}26.36^{* *} \\
V=0.15\end{array}$ \\
\hline Cereals or nuts & 175 & 30.1 & 164 & 29.7 & 339 & 29.9 & 0.03 \\
\hline Fresh fruit or candy bars & 556 & 95.7 & 527 & 95.3 & 1083 & 95.5 & 0.10 \\
\hline Fruit juice or soft drinks & 549 & 94.5 & 514 & 92.9 & 1063 & 93.7 & 1.15 \\
\hline Ice-cream or yoghun & 499 & 85.9 & 426 & 77.0 & 925 & 81.6 & $\begin{array}{l}14.77^{\circ-} \\
V=0.11\end{array}$ \\
\hline $\begin{array}{l}\text { Boiled potatoes or fried potatoes/ } \\
\text { crisps }\end{array}$ & 397 & 68.3 & 326 & 59.0 & 723 & 63.8 & $\begin{array}{l}10.79^{* * *} \\
V=0.10\end{array}$ \\
\hline Margarine or butter & 226 & 38.9 & 208 & 37.6 & 434 & 38.3 & 0.19 \\
\hline Fatty meat or lean meat & 488 & 84.0 & 463 & 83.7 & 951 & 83.9 & 0.02 \\
\hline $\begin{array}{l}\text { Eating four eggs or less per } \\
\text { week or eating more than } \\
\text { four egogs per week }\end{array}$ & 292 & 50.3 & 306 & 55.3 & 598 & 52.7 & 2.93 \\
\hline
\end{tabular}




\section{Usual food choices of the pupils}

It was found that most of the participants $(56.7 \%)$ consumed an average level of usual food according to sex and usual food choices. It is surprising to note that although more than $60 \%$ of the pupils knew that boiled potatoes were more healthy than fried potatoes or crisps, $71.5 \%$ of them consumed fried potatoes very often. Also, although about $82 \%$ of the participants knew that yoghurt was more healthy than icecream (Table 1), more llian a half of them indicated that they consumed ice-cream very often (Table 2).

Girls were more likely to report eating ice-cream, fried potatoes and salty fish (63.7\%, $76.3 \%$ and $39.8 \%$ respectively) than boys $(43.4 \%, 67.0 \%$ and $26.8 \%$ respectively) and the differences were statistically significant. On the other hand, about $32 \%$ of the pupils consumed more than four eggs per week, with a significantly higher percentage for boys than girls $(35.4 \%$ and $29.0 \%$ respectively) $\left(X_{1}^{2}=5.20, P<0.05\right)$. A high consumption of the fat of chicken and meat was found to be more characteristic of boys than girls; $23.5 \%$ of boys ate chicken without removing the fat as compared with $15.8 \%$ of girls $\left(\chi_{1}^{2}=10.57, P<0,01\right)$. Also, $15.5 \%$ of boys ate the fat of meat as compared with $11.7 \%$ of girls (Table 2).

\section{Dietary self-efficacy scale}

Table 3 illustrates the principal components factor analysis with varimax rotation for the dietary self-efficacy part of the questionnaire. The results revealed that four factors with eigenvalues greater than one were extracted. Factor I represents low fat or low sodium foods (go foods) and included six items with eigenvalue of 3.15 and accounted for $18.5 \%$ of the total variance; the item loading ranged from 0.38 to 0.65 . Factor 2 represents low calories or low sodium intake (four items); the item loading ranged from 0.45 to 0.64 . Factor 3 represents low cholesterol in the diet (four items). Factor 4 denotes an additional low fat preference (three items). The overall internal consistency of all the items (standardized Cronbach alpha 0.76 ) indicates sufficiently reliable questionnaires.

Table 4 demonstrates the distribution of the pupils according to sex and the dietary self-efficacy scale. It was found that for almost all the items boys were more likely to eat hcalthy food than girls. The percentage of pupils that reported being "very sure" ranged from a high of $70.1 \%$ regarding drinking fruit juice instead of soft drinks to a low of $16.5 \%$ regarding eating food without adding salt.

For go food items, about $36 \%$ of the pupils were very sure of being able to eat boiled potatoes instead of fried potatoes or crisps, with a significantly higher percentage among boys than girls (40.1\% and $31.5 \%$ respectively). For the item regarding eating yoghurt instead of ice-cream, about $49 \%$ of boys were very sure as compared to $42 \%$ of girls; the difference was statistically significant $\left(\chi_{2}^{2}-13.90, P<0.01\right.$, with a weak association, $V=0.11$ ).

More than $80 \%$ of the pupils reported not being sure or only a little sure that they would be able to eat food without adding salt. On the other hand, more than a half of the pupils were very sure of eating grilled fish instead of salted fish $(59.3 \%$ among boys versus $50.0 \%$ for girls, $\chi_{2}^{2}=11.94$, $P<0.01$ ).

As regards the intake of low calories or sodium, more than $65 \%$ of the pupils reported being able to eat fresh fruit instead of a candy bar and to drink fruit juice instead of soft drinks.

With respect to low cholestero! intake, more than half of the pupils reported being uncertain (not sure or a little sure) of eating only four eggs per week. Also, more than 
Table 2 Distribution of the pupils according to usual food choice scale and sex

\begin{tabular}{|c|c|c|c|c|c|c|c|}
\hline \multirow{2}{*}{$\begin{array}{l}\text { Which food do you } \\
\text { eat very often? }\end{array}$} & \multicolumn{2}{|c|}{ Males } & \multicolumn{2}{|c|}{ Females } & \multicolumn{2}{|c|}{ Total } & \multirow{2}{*}{ Test of significance } \\
\hline & No. & $\%$ & No. & $\%$ & No. & $\%$ & \\
\hline Salty food & 48 & 8.3 & 43 & 7.8 & 91 & 8.0 & \\
\hline Food with a little salt & 506 & 87.1 & 496 & 89.7 & 1002 & 88.4 & $\chi_{2}^{2}=3.81$ \\
\hline Food without salt & 27 & 4.6 & 14 & 2.5 & 41 & 3.6 & \\
\hline Canned vegetables & 85 & 14.6 & 63 & 11.4 & 148 & 131 & \\
\hline Fresh or frozen vegetables & 496 & 85.4 & 490 & 88.6 & 986 & 86.9 & $\chi_{1}^{2}=2.61$ \\
\hline Highly salted cheese & 68 & 12.0 & 64 & 11.7 & 132 & 11.9 & \\
\hline Stored cheese (moderately salted) & 53 & 9.4 & 38 & 6.9 & 91 & 8.2 & $x_{2}^{2}=2.30$ \\
\hline White cheese & 444 & 78.6 & 445 & 81.4 & 889 & 79.9 & \\
\hline Grilled fish & 417 & 73.2 & 328 & 60.2 & 745 & 66.8 & $\chi_{f}^{2}=21.15^{\star}$ \\
\hline Salted fish & 153 & 26.8 & 217 & 39.8 & 370 & 33.2 & $V=0.14$ \\
\hline Low fat milk & 428 & 74.8 & 300 & 57.0 & 728 & 66.3 & $\chi_{2}^{2}=38.82^{*}$ \\
\hline High tat milk & 144 & 25.2 & 226 & 43.0 & 370 & 33.7 & $V=0.19$ \\
\hline Fresh fruit & 516 & 89.7 & 506 & 92.2 & 1022 & 90.9 & \\
\hline Candy bar & 59 & 10.3 & 43 & 7.8 & 102 & 9.1 & $\chi_{1}^{2}=2.01$ \\
\hline Fruit juice & 455 & 78.7 & 427 & 77.2 & 882 & 78.0 & \\
\hline Soft drinks & 123 & 21.3 & 126 & 22.8 & 249 & 22.0 & $x_{7}^{2}-0.37$ \\
\hline Yoghurt & 328 & 56.6 & 201 & 36.3 & 529 & 46.7 & $\chi_{1}^{2}=46.83^{*}$ \\
\hline Ice-cream & 251 & 43.4 & 352 & 63.7 & 603 & 53.3 & $V=0.20$ \\
\hline Jam or honey alone & 289 & 50.6 & 291 & 54.5 & 580 & 52.5 & \\
\hline $\begin{array}{l}\text { Jam or honey after adding butter or } \\
\text { cream }\end{array}$ & 282 & 49.4 & 243 & 45.5 & 525 & 47.5 & $\chi_{1}^{2}=1.67$ \\
\hline Boiled ootatoes & 191 & 33.0 & 131 & 23.7 & 322 & 28.5 & $x_{1}^{2}-11.09^{* *}$ \\
\hline Fried potatoes/crisps & 388 & 67.0 & 421 & 76.3 & 809 & 71.5 & $V=0.10$ \\
\hline Beans with oil & 402 & 70.0 & 406 & 74.1 & 808 & 72.0 & \\
\hline Beans with butter & 172 & 30.0 & 142 & 25.0 & 314 & 28.0 & $x_{1}^{2}=2.28$ \\
\hline Chicken with its skin & 136 & 23.5 & 87 & 15.8 & 223 & 19.7 & $\chi_{1}^{2}=10.57^{\star *}$ \\
\hline Chicken after removing the skin & 443 & 76.5 & 464 & 84.2 & 907 & 80.3 & $V=0.10$ \\
\hline Food cooked with margarine or oil & 379 & 65.2 & 355 & 64.2 & 704 & 64.7 & \\
\hline Food cooked with butter & 202 & 34.8 & 198 & 35.8 & 400 & 35.3 & $\chi_{1}^{2}=0.13$ \\
\hline Boiled or grilled meat & 382 & 66.3 & 368 & 66.7 & 750 & 66.5 & \\
\hline Fried meat & 104 & 30.7 & 100 & 39.2 & 377 & 33.5 & $x_{1}^{2}=0.03$ \\
\hline Boiled or grilled chicken & 251 & 43.8 & 214 & 39.0 & 465 & 41.5 & \\
\hline Boiled and fried chicken & 322 & 56.2 & 334 & 60.9 & 656 & 58.5 & $\chi_{1}^{2}=2.61$ \\
\hline Moat with fat & 69 & 15.5 & 04 & 11.7 & 153 & 13.6 & \\
\hline Meat without fat & 487 & 84.5 & 484 & 88.3 & 971 & 86.4 & $\chi_{\mathrm{f}}^{2}=3.40$ \\
\hline Four eggs or less per week & 369 & 64.6 & 387 & 71.0 & 756 & 67.7 & $\chi_{1}^{2}=5.20^{\star * *}$ \\
\hline More than four eggs per week & 202 & 35.4 & 158 & 29.0 & 360 & 32.2 & $V=0.07$ \\
\hline
\end{tabular}

The sample size varied from the original $\mathrm{n}=1134$ for certain items as a result of incomplete responses on the quostionngires of como pupils (tho poncentage is calculaleu out of the toral numoer who answered). 
Table 3 Factor analysis of items in the dietary self-efficacy questionnaire

How sure are you that you can:

Communality

Eigenvalue Factor

loading

Factor 1: low fat or low sodium (go foods)

Eat boiled potatoes instead of fried potatoes/crisps?

0.40

0.65

Eat boiled chicken without frying?

0.48

0.64

Eat yoghurt instead of ice-cream?

0.45

0.37

0.53

Eat boiled or grilled meat instead of fried meat?

0.23

0.51

Eat food without adding salt?

0.35

0.40

Eat grilled fish instead of salted fish?

0.38

Factor 2: low calories or low sodium

Eat fresh fruit instead of a candy bar?

0.46

0.64

Drink fruit juice instead of soft drinks?

0.49

1.32

0.64

Eat tresh or trozen vegetables instead of canned

0.32

0.48

vegetables?

Eat white cheese instead of salted cheese?

0.31

0.45

Factor 3: low cholesterol intake

Drink low fat milk instead of high fat milk?

0.46

0.64

Eat vegetables cooked with oil or margarine

0.45

1.14

0.62

instead of butter?

Eat beans with oil instead of butter?

0.38

0.49

Eat only four eggs per week?

0.31

0.47

Factor 4: additional low fat preference

Remove and discard the skin of chicken?

0.50

0.69

Remove and discard the fat of meat?

0.48

1.06

0.68

Eat jam or honey without adding butter or cream?

0.30

0.34

$67 \%$ were uncertain of being able to eat vegetables cooked with oil or margarine instead of butter or to drink low fat milk instead of high fat buffalo milk.

Concerning low fat preference, girls were more sure than boys of their ability to remove the skin of chicken or fat of meat (68.1\% and $67.5 \%$ respectively) as compared to boys $(60.2 \%$ and $64.7 \%$ respectively) but the difference was only significant for the first item $\left(\chi_{2}^{2}=12.35\right.$, $P<0.01$ ).

To clarify the most relevant concerns of the pupils, items were ordered by mean response. The ordered list of items is shown in Table 5 with the greater means indicating higher self-efficacy and perceived ability to adopt preventive behaviour, while the lower means indicate perceived inability to adopt protective behaviours against heart disease. The areas of greatest perceived competence were the first three items, which had means ranging from 2.51 to 2.60 , indicating that pupils were very sure of their ability to drink fruit juice instead of soft drinks, eat fresh fruit instead of a candy bar and to remove or not eat the fat of meat. On the other hand, the areas of highest vulnerability (lowest means 1.88 and 1.74 ) indicated that the pupils were stilt highly

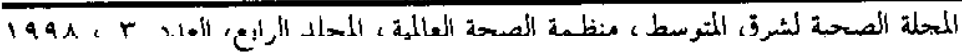


Table 4 Distribution of pupils according to dietary self-efficacy scale and sex

\begin{tabular}{|c|c|c|c|c|}
\hline $\begin{array}{l}\text { How sure are you } \\
\text { that you can: }\end{array}$ & $\begin{array}{l}\text { Males } \\
\text { No. } \%\end{array}$ & $\begin{array}{l}\text { Females } \\
\text { No. } \%\end{array}$ & $\begin{array}{l}\text { Total } \\
\text { No. } \%\end{array}$ & $\begin{array}{c}\text { Test of significance } \\
\chi_{2}^{2}\end{array}$ \\
\hline
\end{tabular}

Factor 1: low fat or sodium (go foods)

Eat boiled potatoes instead of fried potatoes/crisps?

Not sure
A little sure
Vory sure

Eat boiled chicken without frying?

Not sure

A little sure

Very sure

Eat yoghurt instead of ice-cream?

Not sure

A little sure

Very sure

Eat boiled or grilled meat instead of fried meat?

Not sure

A little susre

Very sure

Eat food without adding salt?

Not sure.

A little sure

Very sure

Eat orilled fish instead of salted fish? Not sure

A little sure

Very sure

Factor 2: low calories or low sodium

Eat fresh fruit instead of a candy bar?

Not sure

A little sure

Very sure

Drink fruit juice instead of soft drinks?

Not sure

A little sure

Very sure $\begin{array}{lll}176 & 30.3 & 218\end{array}$

$\begin{array}{lll}172 & 29.6 & 159\end{array}$

$233 \quad 40.1 \quad 174$

$39.6 \quad 394$

$28.9 \quad 331$

$31.5 \quad 407$

235

163

180

40.7243

$20.2 \quad+47$

31.1160

$43.9 \quad 478$

$26.0 \quad 310$

$28.9 \quad 340$

156

142

281

$27.0 \quad 205$

$24.5 \quad 113$

$48.5 \quad 232$

$37.3 \quad 301$

$20.5 \quad 255$

$42.2 \quad 513$

$\begin{array}{lll}99 & 17.2 & 109\end{array}$

167

311

28.0187

53.9254

19.8208

$34.0 \quad 364$

$46.2 \quad 565$

$204 \quad 35.1 \quad 281$

$50.8 \quad 485$

$33.6 \quad 462$

$15.6 \quad 187$

101

$47.5 \quad 186$

$17.4 \quad 86$

133

102

$23.0 \quad 172$

$\begin{array}{ll}17.7 & 102\end{array}$

$31.4 \quad 305$

$18.6 \quad 204$

342

59.3273

$50.0 \quad 615$

27.1

18.1

54.7

34.8

29.2

36.0

$12.75^{*}$

$V=0.11$

42.2

27,3

30.0

32.0

22.6

45.4

$13.90^{*}$

$V=0.11$

18.5

31.4

50.1

$6.7 a^{\star \star}$

$V=0.08$

42.8

40.7

16.5

$30.29^{\star \star \star}$

$V=0.16$

$\begin{array}{lll}76 & 13.1 & 68\end{array}$

$12.3 \quad 111$

12.7

$\begin{array}{llllll}114 & 19.6 & 119 & 21.5 & 233 & 20.5\end{array}$

$\begin{array}{llllll}391 & 67.3 & 366 & 66.2 & 757 & 66.8\end{array}$

$\begin{array}{ll}10.7 & 109\end{array}$

9.6

19.1119

21.5230

20.3

$\begin{array}{lll}67.8 & 795 & 70.1\end{array}$

0.69

420

$\begin{array}{ll}72.3 & 375\end{array}$

Eat fresh or frozen vegetables instead of canned vegetables?

Not sure

A little sure

102

124

$17.6 \quad 110$

$19.9 \quad 212$

18.7

Very sure

$\begin{array}{llllll}355 & 61.1 & 316 & 57.1 & 671 & 59.2\end{array}$ 
Table 4 (Continued)

\begin{tabular}{|c|c|c|c|c|}
\hline How sure are you & Males & Fomales & Total & Test of significance \\
\hline that you can: & No. $\%$ & No. $\%$ & No. $\%$ & $\chi_{2}^{2}$ \\
\hline
\end{tabular}

Eat white cheese instead of salted cheese?

Not sure

A little sure

Very sure

120

$19.8 \quad 95$

17.3209

18.6

341

20.9105

$19.2 \quad 225$

20.0

2.15

Factor 3: low cholesterol intake

Drink low fat milk instead of high

fat milk?

Not sure

A little sure

Very sure

59.3348

$63.5 \quad 689 \quad 61.4$

$\begin{array}{rrrrrrr}242 & 42.2 & 211 & 9.1 & 453 & 40.7 & \\ 160 & 27.9 & 139 & 25.7 & 299 & 26.8 & 3.46 \\ 172 & 29.9 & 190 & 35.2 & 362 & 32.5 & \end{array}$

Eat vegetables cooked with oil or margarine instead of butter?

Not sure

A little sure

$\begin{array}{lll}180 & 31.0 & 175\end{array}$

$31.8 \quad 355$

31.4

Very sure

36.4195

$35.4 \quad 406$

35.9

0.13

$32.8 \quad 370$

32.7

Eat beans with oil instead of butter?

Not sure

A little sure

\section{$85 \quad 14.7 \quad 103$}

$18.8 \quad 188$

16.7

$22.0 \quad 126$

$23.0 \quad 253$

22.5

very sure

300

$63.3 \quad 319$

56.2683

60.0

Eat only four eggs per week?

Not sure

$\begin{array}{lll}141 & 24.5 & 154\end{array}$

28.1295

26.3

157

$27.3 \quad 124$

$22.0 \quad 201$

25.0

Very sure

$48.2 \quad 269$

49.2546

48.7

Factor 4: additional low fat preference

Remove and discard the skin of chicken?

Not sure
A little sure
Very sure

127

102

$22.0 \quad 116$

$21.1 \quad 243$

21.6

$\begin{array}{lll}347 & 60.2 & 374\end{array}$

$10.7 \quad 161$

14.3

$12.35^{*}$

68.1 721

64.1

$V=0.11$

Remove and discard the fat of meat?

$\begin{array}{lrrrrrrr}\text { Not sure } & 85 & 14.7 & 86 & 15.6 & 171 & 15.2 & \\ \text { A little sure } & 119 & 20.6 & 93 & 16.9 & 212 & 18.8 & 2.51 \\ \text { Very sure } & 374 & 64.7 & 371 & 67.5 & 745 & 66.0 & \end{array}$

Eat jam or honey without adding butter or cream?

\begin{tabular}{llllllll} 
Not sure & 141 & 24.4 & 154 & 28.1 & 295 & 26.2 & \\
A little sure & 122 & 21.1 & 115 & 21.0 & 237 & 21.0 & 2.16 \\
Very sure & 315 & 54.5 & 279 & 50.9 & 594 & 52.8 & \\
\hline
\end{tabular}

"P $<0.01 \quad * \mathrm{P}<0.05 \quad * * \mathrm{P}<0.001$

The sample size varied from the original $n=1134$ for certain items as a result of incomplete responses on the questiometires of some pupils (pertentage is calculated from the total number who answered).

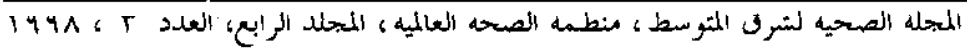


Table 5 Self-efficacy items ordered by mean scale score

\begin{tabular}{|c|c|}
\hline How sure are you that you can: & $\begin{array}{c}\text { Mean } \\
(n=1068)^{n}\end{array}$ \\
\hline Drink frult julce Instead of soft drinks? & $? 2.60$ \\
\hline Eat fresh fruit instead of a candy bar? & 2.54 \\
\hline Remove and discard the fat of meat? & 2.51 \\
\hline Eat beans with oil instead of butter? & 2.44 \\
\hline $\begin{array}{l}\text { Eat white cheese instead of salted } \\
\text { cheese? }\end{array}$ & 2.43 \\
\hline $\begin{array}{l}\text { Remove and discard the skin of } \\
\text { chicken? }\end{array}$ & 2.43 \\
\hline $\begin{array}{l}\text { Eat fresh of frozen vegetables } \\
\text { instead of canned vegetables? }\end{array}$ & 2.40 \\
\hline $\begin{array}{l}\text { Eat boiled or grilled meat instead } \\
\text { of fried meat? }\end{array}$ & 2.32 \\
\hline Eat grilled fish instead of salted fish? & 2.28 \\
\hline $\begin{array}{l}\text { Eat jam or honey without adding } \\
\text { butter or cream? }\end{array}$ & 2.27 \\
\hline Eat only four eggs per week? & 2.22 \\
\hline Eat yoghurt instead of ice-cream? & 2.13 \\
\hline $\begin{array}{l}\text { Eat vegetables cooked with oil or } \\
\text { margarine instead of butter? }\end{array}$ & 2.01 \\
\hline $\begin{array}{l}\text { Eat boiled potatoos inctoad of fried } \\
\text { potatoes/crisps? }\end{array}$ & 2.01 \\
\hline $\begin{array}{l}\text { Drink low fat milk instead of high } \\
\text { fat milk? }\end{array}$ & 1.92 \\
\hline Eat boiled chicken without frying? & 1.88 \\
\hline Eat food without adding salt? & 1.74 \\
\hline
\end{tabular}

Total number of pupils who completed the selfefficacy questionnaire

uncertain of their ability to eat boiled chicken without frying and to eat food without adding salt.

Overall, most of the responses of the pupils were near the middle of the scale, about $54 \%$ of the pupils had a moderate score on the self-efficacy scale. This pattern suggests a greater tendency for subjects to use the middle part (a little sure) of the scale items than the higher end (very sure) or the lower end (not sure). About $42 \%$ of the pupils had a high score on the self-efficacy scale and only $4 \%$ had a low score.

\section{Factors affecting the psychosocial score}

Table 6 shows that both boys and girls had a similar overall mean score for both the knowledge and behaviour scale. On the other hand, boys had a significantly higher mean score on the self-efficacy scale $(38.59 \pm 5.45)$ than girls $(37.70 \pm 6.06)$ $(t=2.51, P<0.05)$. Likewise, ANOVA followed by Tukey test illustrated that pupils of high socioeconomic class exhibited a significantly higher mean score for all the psychosocial factors as compared with those of low socioeconomic class. For the knowledge scale, the score was $15.93 \pm$ 3.70 for the high socioeconomic class com. pared to $14.70 \pm 3.91$ for the low socioeconomic class $(F=10.19, P<0.01)$, for the self-efficacy scale the score was $38.54 \pm$ 5.78 for the high socioeconomic class as compared to $37.59 \pm 5.87$ for the low socioeconomic class $(F=3.49, P<0.05)$ and for the behaviour scale the scores were $22.09 \pm 3.99$ and $21.34 \pm 4.14$ for the high and low socioeconomic classes respectively $(F=2.98, P<0.05)$.

Table 7 shows that the education of the mother was the only significant predictor of high total knowledge scores, but this only explained $1 \%$ of the variation. The relationship between self-efficacy and usual food choices was clarified by the result of stepwise multiple regression in Table 7. It reveals that the first best predictor of a high self-efficacy score was a high score on usual food choices $(r=0.44)$, followed by sex, where boys tended to have better scores than girls. The third factor to enter the model was the knowledge score as a high 


\begin{tabular}{lccc}
\hline $\begin{array}{l}\text { Table } 6 \text { Mean and standard deviation of psychosocial total } \\
\text { scores by sex and social class }\end{array}$ \\
\hline Variable & \multicolumn{3}{c}{ Psychosocial factor } \\
\cline { 2 - 4 } & $\begin{array}{c}\text { Knowledge } \\
\text { Mean } \pm s\end{array}$ & $\begin{array}{c}\text { Self-efficacy } \\
\text { Mean } \pm s\end{array}$ & $\begin{array}{c}\text { Behaviour } \\
\text { Mean } \pm s\end{array}$ \\
\hline Sex & & $38.59 \pm 5.45$ & $21.98 \pm 4.09$ \\
Mailes & $15.55 \pm 3.68$ & $(n=549)$ & $(n=534)$ \\
Females & $15.52 \pm 4.00$ & $37.70 \pm 6.06$ & $21.72 \pm 4.07$ \\
& $(n=553)$ & $(n=519)$ & $(n-498)$ \\
$t$-value & 0.14 & $2.51^{*}$ & 1.01 \\
Social class & & $37.59 \pm 5.87$ & $21.34 \pm 4.14$ \\
Low & $14.70 \pm 3.91$ & $(n=248)$ & $(n=235)$ \\
& $(n=264)$ & $37.60 \pm 5.51$ & $21.74 \pm 4.24$ \\
Middle & $15.34 \pm 3.99$ & $(n=189)$ & $(n=185)$ \\
High & $(n=201)$ & $38.54 \pm 5.78$ & $22.09 \pm 3.99$ \\
& $15.93 \pm 3.70$ & $(n=631)$ & $(n=612)$ \\
F-ratio & $(n=669)$ & $3.49^{*}$ & $2.98^{*}$ \\
\hline *P $<0.05$ & $10.19^{* *}$ & $s=s t a n d a r d$ deviation
\end{tabular}

knowledge score was associated with an increase in self-efficacy score $(r=0.37)$. These three predicted variables could explain $25 \%$ of variation in the self-efficacy scale score.

As regards the independent variables affecting the behaviour score, it was found that the presence of audiovisual equipment was the first predictor followed by the score of knowledge and self-efficacy. Having a high score on both the knowledge test and self-efficacy scale was associated with a high frequency of eating healthy foods. When the partial correlation was performed between self-efficacy and behaviour scores, it was $0.37,(P<0.01)$ after controlling for knowledge and audiovisual equipment, whereas it was $0.20(P<0.01)$ after controlling for self-efficacy score. Overall, the regression analysis model produced $R^{2}$ $=0.23$.

\section{Test-retest rellability for dietary self-efficacy scale (Table 8)}

Approximately $65 \%$ of the items showed significant change in the mean score of test and retest scale. This indicated instability about the mean for the dietary self-efficacy scale. The significant change in the mean score tended to be from low to high for all the items except for eating grilled fish instead of salted fish. The overall score for the second completion (retest) was statistically higher $(39.98 \pm 5.90)$ than that of the first one $(38.11 \pm 5.81)(P<0.001)$. The percentage agreement between responses on first and second administration of the questionnaire ranged from $42 \%$ to $72 \%$, the 
Table 7 Summary of stepwise multiple regression analysis of pupils dietary knowledge, selfefficacy and behaviour scores on the different independent factors

\begin{tabular}{|c|c|c|c|c|c|c|c|c|}
\hline $\begin{array}{l}\text { Dependent } \\
\text { variable }\end{array}$ & $\begin{array}{l}\text { Independent } \\
\text { variable }\end{array}$ & $\boldsymbol{B}$ & $s_{\bar{x}}(B)$ & $\beta$ & $t$ & $\begin{array}{c}\text { Multiple } \\
\qquad R\end{array}$ & $F^{R}$ & $\boldsymbol{F}$ \\
\hline Knowledge & $\begin{array}{l}\text { Education of the } \\
\text { mother }\left(x_{4}\right) \\
\text { Constant }\end{array}$ & $\begin{array}{r}0.9829 \\
14.8028\end{array}$ & $\begin{array}{l}0.2602 \\
0.2244\end{array}$ & 0.1118 & $3.78^{\star}$ & 0.11 & 0.01 & $14.28^{* *}$ \\
\hline Self-efficacy & $\begin{array}{l}\text { Behaviour score }\left(x_{7}\right) \\
\text { Sex }\left(x_{1}\right) \\
\text { Knowledge score }\left(x_{6}\right) \\
\text { Constant }\end{array}$ & $\begin{array}{r}0.5053 \\
-0.6212 \\
0.3647 \\
22.5003\end{array}$ & $\begin{array}{l}0.0408 \\
0.3139 \\
0.0441 \\
0.9455\end{array}$ & $\begin{array}{r}0.3605 \\
-0.0545 \\
0.2402\end{array}$ & $\begin{array}{l}12.39^{* \star} \\
1.98^{\star} \\
8.29^{\star \star}\end{array}$ & 0.50 & 0.25 & $109.41^{* *}$ \\
\hline Behaviour & $\begin{array}{l}\text { Audiovisual aids }\left(x_{5}\right) \\
\text { Knowledge score }\left(x_{6}\right) \\
\text { Self-efficacy score }\left(x_{0}\right) \\
\text { Constant }\end{array}$ & $\begin{array}{l}1.1448 \\
0.2103 \\
0.2657 \\
8.2621\end{array}$ & $\begin{array}{l}0.4761 \\
0.0323 \\
0.0213 \\
0.8004\end{array}$ & $\begin{array}{l}0.0670 \\
0.1942 \\
0.3724\end{array}$ & $\begin{aligned} 2.41^{*} \\
6.51^{* *} \\
12.49^{* *}\end{aligned}$ & 0.48 & 0.23 & $99.28^{* *}$ \\
\hline
\end{tabular}

"P $<0.05 \quad$ "P $<0.001 \quad \mathrm{~s}_{\overline{\mathrm{x}}}=$ standard error of the mean

$B=$ partial regression coefficient $\quad{ }^{x} s_{x}(B)=$ standard arror of $B$

$\mathrm{R}^{2}$ - coofficient of delomination

Prediction equation:

Knowledge $\mathrm{Y}=14.8028+0.9829 \mathrm{x}_{4}$

Self-efficacy $Y=22.5003+0.5053 x_{7}-0.6212 x_{1}+0.3647 x_{6}$

Bohaviour $\mathrm{V}-8.2621+1.1448 \times_{5}+0.2103 \mathrm{x}_{6}+0.2667 \mathrm{x}_{8}$

lower percentage of agreement was for the question about removing and not eating the skin of chicken, while the higher percentage was for the question about drinking fruit juice instead of soft drinks.

Correlation between scale scores at the first and second completion varied from 0.27 to 0.48 . For the majority of the items, the pupils showed a moderate reliability, as Cronbach alpha ranged from 0.42 to 0.65 . The lowest correlation was for eating boiled or grilled meat instead of fried meat $(r=0.27$, Cronbach alpha $=0.42)$, whereas the highest was for eating grilled fish instead of salted fish ( $r=0.48$, Cronbach alpha $=0.65$ ).

When all the 17 impact items were combined into one scale, the correlation between scores in the first and second administration was 0.65 and Cronbach alpha reached 0.79 , indicating good reliabili- ty. However, the overall reliability results as shown in Table 9 indicate that boys were more consistent than girls (Cronbach alpha $=0.80$ and 0.77 respectively). Although pupils of higher socioeconomic class exhibited a significant change of scores from $38.68 \pm 5.74$ at the first administration of the questionnaire to $39.81 \pm 5.78$ at the second one $(P<0.001)$, they had a higher reliability (Cronbach alpha $=0.80$ ) than pupils of middle and low socioeconomic class (Cronbach alpha $=0.78$ and 0.74 respectively).

\section{Discussion}

There are several physiological risk factors for cardiovascular diseases such as high blood pressure, hypercholesterolaemia and obesity. Behaviour contributing to these 
Table 8 Test-retest reliability for dietary self-efficacy scale among the study sample

How sure are you that you can: $\begin{gathered}\% \text { of } \\ \text { agreement Mean } \pm s\end{gathered} \begin{gathered}\text { Restest } \\ \text { Mean } \pm s\end{gathered} \quad r \begin{gathered}\text { Cronbach } \\ \text { alpha }\end{gathered} \quad \begin{gathered}\text { Hotelling } \\ \text { T-squared }\end{gathered}$

Factor 1: low fat or low sodium

(Go foods)

Eat bolled potatoes instead

fried potatoes/crisps?

57

Eat boiled chicken without frying?

$59 \quad 1.89+0.84 \quad 1.88 \pm 0.80 \quad 0.45$

0.59

0.89

Eat yoghuit instead of ice-cream?

58

$2.13 \pm 0.88$

$2.10 \pm 0.86$

0.45

0.62

0.08

Eat boiled or grilled meat instead of fried meat?

56

$2.31 \pm 0.77 \quad 2.32 \pm 0.75 \quad 0.27$

0.62

0.68

Eat food without adding salt?

57

$1.71 \pm 0.71 \quad 1.66 \pm 0.70 \quad 0.34$

0.42

0.01

Eat grilled fish instead of salted fish?

63

$2.80 \pm 0.87 \quad 2.35 \pm 0.81 \quad 0.48$

0.51

2.61

Factor 2: low calories or low sodium

Eat tresh trult Instead of a candy bar?

Drink fruit juice instead of solt drinks?

72

$2.61 \pm 0.64 \quad 2.64 \pm 0.62 \quad 0.41$

0.59

1.20

Eat fresh or frozen vegetables instead of canned vegetables?

57

$2.40 \pm 0.78 \quad 2.54 \pm 0.71 \quad 0.27$

0.43

$18.92^{* * *}$

Eat white cheese instead of salted cheese?

Factor 3: low cholesterol intake

Drink low fat milk instead of high fat milk?

$\begin{array}{llllll}55 & 1.90 \pm 0.85 & 1.96 \pm 0.84 & 0.42 & 0.59 & 2.50\end{array}$

Eat vegetables cooked with nil or margarine instead of butter?

$2.02 \pm 0.80$

$2.14 \pm 0.79 \quad 0.35$

0.52

$15.38^{* * *}$

Eat beans with oil instead of butter?

60

$2.43 \pm 0.76$

$2.49 \pm 0.73 \quad 0.34$

0.51

$4.19^{*}$

Eat only four eggs per week?

56

$2.10 \pm 0.84 \quad 2.25 \pm 0.00 \quad 0.38$

0.47

3.08

Factor 4: additional low fat preference

Remove and discard the skin of chicken?

Remove and discard the fat of meat?

Eat jam or honey without adding butter or cream?

Total scale score $38.11 \pm 5.8139 .98 \pm 5.90 \quad 0.65$

$* P<0.05 \quad * P<0.01 \quad * * P<0.001$

$\mathrm{r}=$ correlation coefficient

$\mathrm{s}=$ standard deviation 
Table 9 Test-retest rellability for overall dietary self-efficacy scale score by sex and social class

\begin{tabular}{lcccccc}
\hline Variable & $n$ & \multicolumn{2}{c}{ Total score } & $r$ & $\begin{array}{c}\text { Cronbach } \\
\text { alpha }\end{array}$ & $\begin{array}{c}\text { Hotelling } \\
\text { T-squared }\end{array}$ \\
\cline { 3 - 5 } & & $\begin{array}{c}\text { Test } \\
\text { Mean } \pm s\end{array}$ & $\begin{array}{c}\text { Retest } \\
\text { Mean } \pm s\end{array}$ & & & \\
\hline Sex & & & & & & \\
$\quad$ Males & 379 & $38.61 \pm 5.70$ & $39.56 \pm 5.65$ & 0.67 & 0.80 & $15.70^{*}$ \\
$\quad$ Females & 357 & $37.58 \pm 6.08$ & $38.36 \pm 6.11$ & 0.63 & 0.77 & $7.60^{* *}$ \\
Social class & & & & & & \\
$\quad$ Low & 164 & $37.45 \pm 6.02$ & $37.76 \pm 5.88$ & 0.64 & 0.78 & 0.59 \\
$\quad$ Middle & 124 & $36.94 \pm 5.52$ & $37.59 \pm 5.86$ & 0.58 & 0.74 & 1.91 \\
High & 448 & $38.68 \pm 5.74$ & $39.81 \pm 5.78$ & 0.67 & 0.80 & $26.08^{* *}$ \\
\hline
\end{tabular}

${ }^{*} \mathrm{P}<0.001 \quad{ }^{*} \mathrm{P}<0.01$

$\mathrm{r}=$ correlation coetiticlent

$\mathbf{s}=$ standard deviation

risk factors include consumption of excessive calories, total fat, saturated fat and sodium [3]. A prerequisite for any health promotion campaign should be to obtain information about the current level of knowledge and understanding of the issues by the public. This will enable the most appropriate health messages to be put forward [I].

In a study done by Tate and Cade to determine the level of knowledge in the general population concerning dietary fat and the risk of coronary heart disease, they found that the overall knowledge levels were high with no difference between men and women, although women were more able to select the best food items than men [I]. Also, the knowledge level was higher among the higher socioeconomic classes than the low socioeconomic classes. The results of the present study revealed that the overall knowledge levels were moderate. In agreement with the results of the aforementioned study, both boys and girls had a similar total knowledge score, although girls were more able to select the best food items than boys. This could be explained by the fact that girls are more likely to help their mothers during shopping and cooking than boys and so are more aware of food and its nutrient contents.

The results of the present study also concur with the results of Tate and Cade concerning the positive correlation between socioeconomic class and knowledge score. This could be explained by the fact that parents of high sncineconomic class are more educated and have a better knowledge of healthy food that can be transmitted to their children than parents of low socioeconomic class. This is confirmed by the finding that education of the mother was the only significant predictor of high total knowledge score, because the mother is generally concerned with the nutrition of her family. Another explanation is that other sources of knowledge such as television and radio are more available to those of the higher socioeconomic classes. This is also confirmed by the present results which showed that audiovisual equipment was the first best predictor for usual food choices (dietary behaviour) score followed by knowledge and self-efficacy. This reflects the importance of audiovisual equipment 
(mass media) as a source of health education for improvement of knowledge, selfefficacy and behaviour.

Although health education interventions may succeed in increasing children's knowledge and producing changes in behavioural intentions, the behavioural changes may not be maintained unless the school environment and children's parents reinforce such intentions[12]. This could explain the result of our study which revealed that although a high percentage of pupils knew that boiled potatoes were more healthy than fried potatoes or crisps and yoghurt more healthy than ice-cream, more than half of them ate fried potatoes or crisps and ice-cream very often due to the lack of reinforcement of the behavioural intentions.

In a study by Burdine et al., males were found to be more likely than females to eat healthy foods frequently, both at home and at school [13]. Our findings are consistent with this; girls were more likely to report eating ice-cream, fried potatoes, crisps and salty fish than boys. Also, overall dietary self-efficacy mean scores for boys were higher than those of girls. It is possible that males may be unore conscious of diet for athletic appearance [13].

On the other hand, our study showed that a high consumption of fat was found to be more characteristic of boys than girls. Also, girls were more sure than boys of their ability to remove the skin of chicken or the fat of meat. Posner et al. reported that a substantially larger proportion of women than men satisfy the guidelines for dietary cholesterol ( $80 \%$ versus $49 \%$ ) and sodium ( $94 \%$ versus $55 \%$ ) [14].

Our study confirms the result of Parcel et al. who found sex was a significant predictor of usual food choices with girls tending to have better scores than boys. This could be explained by the fact that females may be more interested in restricting their diets and losing weight because of social influences such as peer pressure and concern for a slim appearance. In addition, males may simply eat more and thus consume more of some types of food [8].

Our study showed that about $56.7 \%$ of the pupils scored on the moderate level for usual food choices. This is consistent with the results of a study in California and Texas which found "twin peaks" near the middle of the scale [8].

Self-efficacy influences a variety of human actions, particularly the self-control of behaviour. What people believe themselves capable of doing strongly influences their decisions and choices about what to do. Self-efficacy positively enhances a person's decision to act, the amount of effort made, the persistence of the effort and the emotional and cognitive arousal [15].

Factor analysis of the self-efficacy scale revealed that four factors with eigenvalues greater than 1 were extracted. The factor loading ranged from 0.38 to 0.69 . These results provide evidence of construct validity. The overall internal consistency of the all items (standardized Cronbach alpha = 0.76 ) indicates sufficiently reliable questionnaires. The results of a study in the United States revealed only one factor with an eigenvalue of 5.137 which accounted for $97 \%$ of variance in the scale [8]. Values of the factor loading ranged between 0.51 and 0.65 with Cronbach alpha $=0.84$.

The present study indicated a greater tendency of subjects to use the middle part (a little sure) of the scale. This differs from the finding of Parcel et al. who found the distribution of the child dietary self-efficacy scale was skewed to the right, indicating more subjects scored on the high end of the scale, suggesting a greater tendency for subjects to use the higher end (very surc) of the scale items [8]. 
As regards the test-retest reliability of the child dietary self-efficacy scale, it was found that $r=0.65$ and Cronbach alpha reached 0.79 , indicating good reliability. These results are consistent with Parcel et al. who found the reliability estimate for the child dietary self-eficacy scale was $r=0.63$ [8]. Boys were more consistent on the selfefficacy scale than girls; this may be attributed to the high stability or strong personality of boys in our culture.

Self-efficacy is a connection between knowledge and action since the belief that one can adopt a behaviour occurs before one actually attempts the behaviour. Selfefficacy also affects the choice of behaviour [7]. This is confirmed by the results of our study which showed that knowledge was a predicator of self-efficacy $(r=0.37)$. Also self-efficacy and knowledge together were predictors of usual food choices. Parcel et al. reported that self-efficacy was the strongest predictor of usual food choices $(r$ $=0.34$ ) [8].

An individual's performance of a behaviour usually provides the best indicator of the ability to do it. The converse is also true [7]. This is confirmed by the results of the present study which revealed that usual food choices were the best predictor of selfefficacy $(r=0.44)$.

The pupils in our study had areas of great perceived competence concerning their ability to drink fruit juice instead of soft drinks, eat fresh fruit instead of candy bars and remove or not eat the fat of meat. Also the highest proportion gave the cor- rect knowledge answer (about $96 \%$ ) for the question about the relative healthiness of fresh fruit or candy bars. This confirms the strong relationship between knowledge and self-efficacy. This could also be explained by the availability and low price of fruits, coupled with good information about their importance as sources of minerals and vitamins. Another finding was that only $15.5 \%$ of boys and $11.7 \%$ of girls ate the fat of meat. This reinforces the strong relationship between self-efficacy and behaviour. On the other hand, their areas of greatest vulnerability concerned their inability to eat boiled chicken without frying and to eat food without salt.

These points should be noted when planning nutrition education programmes addressing preparatory-school pupils.

\section{Recommendation}

Health education strategies for heart disease should be included in a comprehensive school health programme to help develop healthy dietary behaviour and lifestyle from an early age in order to reduce the incidence of coronary heart disease. The programme should focus not only on knowledge of diet and coronary heart disease but also on teaching people how to obtain healthy food. More attention should be paid to culture, customs, socioeconomic factors and beliefs because these are key factors which affect health behaviour.

\section{References}

1. Tate J, Cade J. Public knowledge of dietary fat and coronary heart disease. Journal of health oduoation, 1000, 49(1):32-5.
2. Perry CL, Mullis RM, Maile MC. Modifying the eating behavior of young children. Journal of school health, 1985, 55(10):399-402. 
3. Simons-Morton BG, Parcel GS, O'Hara NM. Implementing organizational changes to promote healthful diet and physical activity at school. Health education quarterly, 1988, 15(1):115-30.

4. Parcel GS et al. School promotion of healthful diet and exercise behavior: an integration of organizational change and social learning theory interventions. Journal of school health, 1987, 57(4):150-5.

5. Simons-Morton BQ et al. Children's frequency of consumption of foods high in fat and sodium. American journal of preventive medicine, 1990, 6(4):218-27.

6. Simons-Morton BG et al. Promoting heathful diet and physical activity among chlldren: results of a school-based Intervention. American journal of public health, 1991, 81(8):986-91.

7. Lawrance L, McLeroy KR. Self-efficacy and health education. Joumal of school health, 1986, 56(8):317-21.

8. Parcel GS et al. Measurement of self-efticacy for diet-related behaviors among elementary school children. Journal of school health, 1995, 65(1):23-7.

9. Perry CL, Stone E, Parcel GS. Schoolbased cardiovascular health promotion: the child and adolescent trial for cardiovascular health (CATCH). Journal of school health, 1990, 60(8):406-13.
10. Parcel GS et al. School promotion of healthful diet and physical activity: impact on learning outcomes and self-reported behavior. Health education quarterly, 1989, 16(2):181-99.

11. Fahmy SI, El-Sherbini AF. Determining simple parameters for social classifications for health research. Bulletin of the High Institute of Public Health, 1983. 13(5):95-107.

12. Stone EJ, Perry CL, Luepker RV. Synthesis of cardiovascular behavioral research for youth health promotion. Health education quarterly, 1989, 16(2):155-69.

13. Burdine JN et al. The effects of ethnicity, sex and father's occupation on heart health knowledge and nutrition behavior of schoolchlldren: the Texas youth health awareness survey. Journal of school health, 1984, 54(2):87-90.

14. Posner BM et al. Healthy people 2000. The rationale and potential efficacy of preventive nutrition in heart disease: the Framingham Offspring-Spouse Study. Archives of internal medicine, 1993, 153(12):1549-56.

15. Thoresen CE, Kirmil-Gray K. Self-management psychology and treatment of childhood asthma. Clinical immunology, 1983, 2:596-606.

\section{Correction}

Oral health survey in 12-year-old children in the Islamic Republic of Iran, 1993-1994. EMHJ Vol.4 No.2. August 1996, page 338, by S.M. Seyedein, M.R. Zali, M.V. Golpaigani, H. Yazdani and S. Nourhalouchi.

The correct name in Arabic of the first author should read سيل محتبي بيدين 